\title{
The ISO/EN 13606 Standard for the Interoperable Exchange of Electronic Health Records
}

\author{
Pilar Muñoz, MSc ${ }^{1}$;; Jesús D. Trigo, MSc¹; Ignacio Martínez, PhD'; \\ Adolfo Muñoz, $\mathbf{P h D}^{\mathbf{2}}$; Javier Escayola, $\mathbf{M S c}{ }^{1}$; José García, $\mathbf{P h D}^{\mathbf{1}}$ \\ ${ }^{1}$ Aragon Institute for Engineering Research (I3A), \\ University of Zaragoza (UZ), Spain. \\ ${ }^{2}$ Telemedicine and Information Society Department, \\ Health Institute "Carlos III" (ISCIII), Madrid, Spain
}

Submitted July 2010. Accepted for publication December 2010.

\begin{abstract}
The standardization of Electronic Health Records (EHR) is a crucial factor for ensuring interoperable sharing of health data. During recent decades, a plethora of initiatives -driven by international organizations - has emerged to define the required models describing the exchange of information between EHRs. These models cover different essential characteristics for building interoperable EHRs, such as architecture, methodology, communication, safety or terminology, among others. In this context, the European reference frame for the standardized exchange of EHR is the recently approved ISO/EN 13606 standard. This multi-part standard provides the syntactic and semantic capabilities (through a dual model approach) as well as terminology, security and interface considerations for the standardized exchange of EHR. This paper provides (a) an introduction to the different standardization efforts related to the interoperable exchange of EHR around the world, and (b) a description of how the ISO/EN 13606 standard provides interoperable sharing of clinical information.
\end{abstract}

\section{ELECTRONIC HEALTH RECORDS AND STANDARDIZATION}

There are many definitions of Electronic Health Records (EHR), but a broadly accepted one is that of the Health Information Management Systems Society (HIMSS): "Health records are longitudinal records of patient health information generated by one or more encounters in any care delivery setting. Included in this information are patient demographics, progress notes, problems, medications, vital signs, past medical history, immunizations, laboratory data and radiology reports" [1]. The traditional health

\footnotetext{
*Corresponding Author: Pilar Muñoz, Aragon Institute for Engineering Research (I3A), c/ María de Luna, 1. 50018 - Zaragoza (Spain). Phone: (+34) 976761000 ext. 5462. Fax: (+34) 976762111. E-mail: pmg@unizar.es. Other authors: jtrigo@unizar.es; imr@unizar.es; adolfo.munoz@isciii.es; javier.escayola@unizar.es; jogarmo@unizar.es.
} 
records were maintained in paper format. As computer-based systems have become popular since the end of the last century, the application of Information and Communication Technologies (ICT) in all social or industrial sectors has resulted in remarkable advantages for the management and exploitation of resources. Within the particular environment of the healthcare sector, the relevant role of ICT has led to the transformation of those traditional paper-based health records into EHRs.

This change to a paperless health work environment has provided a plethora of benefits, such as more agile management of health records, lower maintenance costs or faster administrative response, among others. Besides the noteworthy benefits, a wide variety of challenges and opportunities have emerged. One of the most interesting is the capability of inter-connecting EHR Systems [1]. EHRs are usually generated and maintained within an institution, such as a hospital, integrated delivery network, clinic, or any other provider [3]. These EHRs integrate the longitudinal record of all care services provided over the patient's lifetime, but this record is usually separated in different systems and interconnecting this information is a requisite for effectively retrieving the whole longitudinal record of care. However, the lack of common criteria while developing these systems has hampered efforts to achieve a satisfactory exchange of clinical information. Furthermore, the possibility of building an EHR system by means of any programming language, any architecture design or internal workflow entails a lack of interoperability.

Based on the above considerations, a desirable goal would be to achieve an interoperable exchange of EHR. However, in order to accomplish such an objective, several requirements (technical, architectural, etc.) must be considered and defined. These requirements are formally translated into norms or standards provided by the appropriate organizations such as the Standard Development Organizations (SDO). Depending on their area of influence, SDOs can be international, national or regional. The most relevant organizations for world-wide standardization can be classified as shown in Table 1. These entities are independent (except for the Technical Committees), but their parallel development and results in similar fields of work has propitiated the need for establishing collaborative relationships between them, such as the Vienna Agreement between ISO and CEN [4] that guarantees that the documents developed within one body will be notified for simultaneous approval by the other. A complete relationship scheme of SDOs is detailed in Figure 1.

Communication and cooperation between different EHR systems and their components in a complex and highly dynamic environment requires the adoption of common terminologies and ontologies, advanced security, safety and privacy services and the separation between the logical and terminological points of view. The existence of such a wide variety of requirements implies the definition of specialized standards, classified according to the specific area to which they are related. Table 2 details the actual status of standardization of EHR grouped into the main specification areas: identification, architecture, infrastructure, communication models and security policies, among others $[5,6]$. The incorporation of such standards and models into new EHR system designs would allow a further step to be taken in the utilization of future eHealth systems, preventing the proliferation of non-reusable prototypes. 


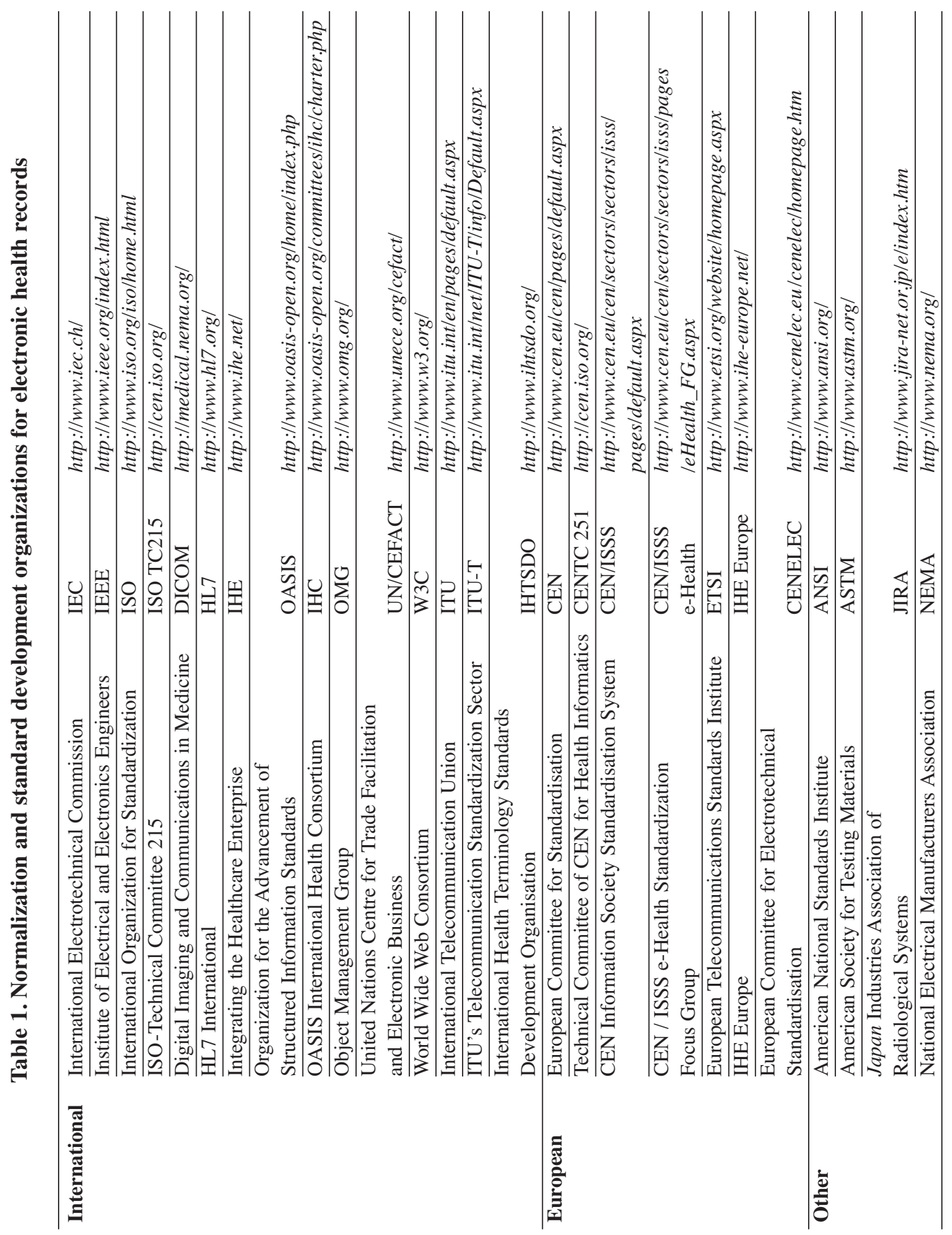




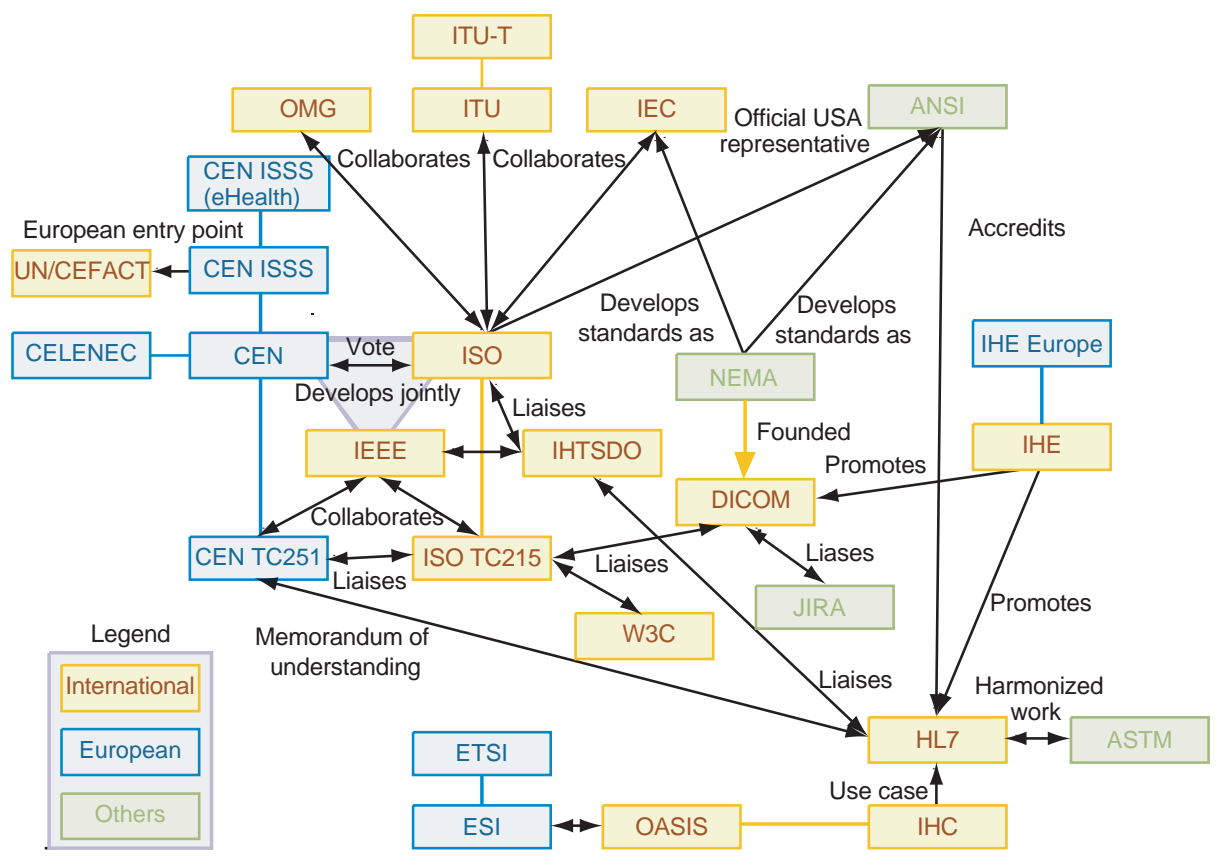

Figure 1. Relationship scheme of normalization and standard development organizations for electronic health records.

Within this context of interoperable exchange of EHRs, a wide range of initiatives have been proposed. Health Level 7 (HL7) [7], founded by American vendors of medical devices and recognized by ANSI, is an international standard for medical message exchange. It specifies a uniform syntax in the seventh level of the protocol stack, for information representation in a simple structure of segments, data type flags, and mapped fields. HL7 is a workable solution for the interoperable exchange of EHR and it is being widely used in the US and Canada. However, the semantic/syntactic model of HL7 can be enhanced by means of a dual model approach that represents clinical information and clinical knowledge separately. This was envisioned by different organizations that proposed a new dual-based model. Such initiatives include the openEHR Foundation, which proposed the openEHR specification [8] and the Technical Committee CEN/TC251, which developed the ISO/EN 13606 standard [9]. While HL7 is widely applied in the US and Canada, openEHR and ISO/EN 13606 are two closely related efforts (ISO/EN 13606 leveraged appropriate parts of openEHR) that are likely to be used in a collaborative fashion in Europe. Additionally, the European Commission encourages interoperability in the healthcare field through publications such as article 16 of 2008/0142 (COD) [10] or 2008/594/EC [11]. The European Commission plans to support large-scale pilots-through European funded projects such as the epSOS project [12] or ARGOS e-Health [13]-and aims to agree on 
Table 2. Relevant standards for electronic health record systems

$($ HI = Health Informatics, IT = Information Technologies, SAGE = Security Algorithms Group of Experts, ESI = Electronic Signatures and Infrastructures)

\begin{tabular}{|c|c|c|}
\hline \multirow[t]{5}{*}{$\begin{array}{l}\text { Requirement } \\
\text { and Analysis }\end{array}$} & ASTM E2212-02a & $\begin{array}{l}\text { Standard Practice for Healthcare } \\
\text { Certificate Policy }\end{array}$ \\
\hline & ISO 18812:2003 & $\begin{array}{l}\text { HI - Clinical analyser interfaces to laboratory } \\
\text { information systems-Use profiles }\end{array}$ \\
\hline & ISO 22857:2004 & $\begin{array}{l}\text { HI - Guidelines on data protection to facilitate } \\
\text { trans - border flows of personal health information }\end{array}$ \\
\hline & ISO TR 20514:2005 & $\begin{array}{l}\text { HI - Electronic health record - Definition, scope } \\
\text { and context }\end{array}$ \\
\hline & ISO TS 18308:2004 & $\begin{array}{l}\text { HI - Requirements for an electronic health record } \\
\text { architecture }\end{array}$ \\
\hline \multirow[t]{3}{*}{ Architecture } & $\begin{array}{l}\text { CEN EN 12967:2006 } \\
\text { (HISA) }\end{array}$ & $\begin{array}{l}\text { HI - Service architecture Part 1: Enterprise } \\
\text { viewpoint - Part 2: Information viewpoint - } \\
\text { Part 3: Computational viewpoint }\end{array}$ \\
\hline & CEN EN 13606-1:2010 & $\begin{array}{l}\text { HI - EHR communication Part 1: } \\
\text { Reference Model }\end{array}$ \\
\hline & CEN EN 13606-4:2010 & $\begin{array}{l}\text { HI - EHR communication Part 4: Security } \\
\text { requirements and distribution rules }\end{array}$ \\
\hline \multirow[t]{10}{*}{$\begin{array}{l}\text { Modelling } \\
\text { and } \\
\text { Methodology }\end{array}$} & ASTM E1715-01 & $\begin{array}{l}\text { An object - oriented model for registration, } \\
\text { admitting, discharge, and transfer functions } \\
\text { in HCIS }\end{array}$ \\
\hline & ASTM E2085-00a & $\begin{array}{l}\text { Standard guide on security framework for } \\
\text { healthcare information }\end{array}$ \\
\hline & CEN CR 12587 & $\begin{array}{l}\text { CEN Report: Medical Informatics - Methodology } \\
\text { for the development of healthcare messages }\end{array}$ \\
\hline & CEN EN 13940-1:2006 & $\begin{array}{l}\text { HI - System of concepts to support Continuity of } \\
\text { care - Part 1: Basic concepts }\end{array}$ \\
\hline & CEN EN 14463:2006 & $\begin{array}{l}\text { HI - A syntax to represent the content of medical } \\
\text { classification systems (ClaML) }\end{array}$ \\
\hline & CEN ENV 13940:2002 & $\begin{array}{l}\text { HI - System of concepts to support continuity } \\
\text { of care }\end{array}$ \\
\hline & CEN TR 15300 & $\begin{array}{l}\text { HI - Framework for formal modelling of healthcare } \\
\text { security policies (CEN Report) }\end{array}$ \\
\hline & IETF RFC 3281 & $\begin{array}{l}\text { An Internet Attribute Certificate Profile for } \\
\text { Authorization }\end{array}$ \\
\hline & ISO HL7 21731:2006 & $\begin{array}{l}\text { HI - HL7 version } 3 \text { - Reference Information Model } \\
\text { Release } 1\end{array}$ \\
\hline & ISO DIS 27799 & $\begin{array}{l}\text { HI - Security management in health using ISO/IEC } \\
17799\end{array}$ \\
\hline
\end{tabular}

Table 2. (Continued) 
Table 2. Relevant standards for electronic health record systems

$($ HI $=$ Health Informatics, IT = Information Technologies, SAGE = Security Algorithms Group of Experts, ESI = Electronic Signatures and Infrastructures)

(Continued)

\begin{tabular}{ll}
\hline ISO IEC 10118 & IT - Security techniques - Hash-functions \\
\hline ISO IEC 10181 & $\begin{array}{l}\text { IT - Open Systems Interconnection - Security } \\
\text { frameworks for open systems }\end{array}$ \\
\hline $\begin{array}{ll}\text { IT - Telecommunication/information exchange } \\
\text { between systems, transport layer security } \\
\text { protocol }\end{array}$ \\
\hline $\begin{array}{ll}\text { IT - Open Systems Interconnection, Upper layers } \\
\text { security model }\end{array}$ \\
\hline ISO IEC 13335-1:2004 & $\begin{array}{l}\text { IT - Security techniques - Management of } \\
\text { information and communications technology } \\
\text { security }\end{array}$ \\
\hline ISO IEC 15408:2005 & $\begin{array}{l}\text { IT - Security techniques - Evaluation criteria for } \\
\text { IT security }\end{array}$ \\
\hline ISO IEC 27002 $27001: 2005$ & $\begin{array}{l}\text { IT - Security techniques - Information security } \\
\text { management systems - Requirements }\end{array}$ \\
\hline ISO IEC 27003 & $\begin{array}{l}\text { IT - Security techniques - Code of practice for info } \\
\text { security management (ISO/IEC17799:2005IT) }\end{array}$ \\
\hline ISO IEC 27004 & $\begin{array}{l}\text { Information security management systems - } \\
\text { Implementation guidance }\end{array}$ \\
\hline CEN EN 13608:2006 & $\begin{array}{l}\text { Information security management systems - } \\
\text { Measurements }\end{array}$ \\
\hline ISO IEC 27005 & $\begin{array}{l}\text { Information security management systems - } \\
\text { Risk assessment }\end{array}$ \\
\hline Parts 1, 2 and 3. \\
\hline ISO IEC NP 27000 & $\begin{array}{l}\text { IT - Information security management - fundamen- } \\
\text { tals and vocabulary }\end{array}$ \\
\hline ISO IEC TR 13335:1998 & $\begin{array}{l}\text { IT - Guidelines for the management of IT Security - } \\
\text { Parts 3, 4 and 5 }\end{array}$ \\
\hline Security management systems for the supply chain \\
\hline ISO PAS 28000:2005 $28003: 2006$ & $\begin{array}{l}\text { Requirements for bodies providing audit/certification } \\
\text { of supply chain security management system }\end{array}$ \\
\hline $\begin{array}{l}\text { HI - Standard communication protocol - } \\
\text { Computer-assisted electrocardiography }\end{array}$ \\
\hline $\begin{array}{l}\text { HI - Digital imaging - Communication, workflow } \\
\text { and data management }\end{array}$ \\
\hline
\end{tabular}

Table 2. (Continued) 
Table 2. Relevant standards for electronic health record systems

$($ HI $=$ Health Informatics, IT $=$ Information Technologies, SAGE $=$ Security Algorithms Group of Experts, ESI = Electronic Signatures and Infrastructures)

(Continued)

\begin{tabular}{|c|c|}
\hline CEN EN 13609-1:2005 & $\begin{array}{l}\text { HI - Messages for maintenance of supporting } \\
\text { information in healthcare systems - Part } 1\end{array}$ \\
\hline CEN EN 14720-1:2006 & HI - Service request and report messages - Part 1 \\
\hline CEN EN 14822-1:2006 & $\begin{array}{l}\text { HI - General purpose information components - } \\
\text { Parts } 1,2 \text { and } 3 .\end{array}$ \\
\hline CEN ENV 13607:2000 & $\begin{array}{l}\mathrm{HI} \text { - Messages for the exchange of information } \\
\text { on medicine prescriptions }\end{array}$ \\
\hline CEN ENV 13609-2:2000 & $\begin{array}{l}\text { HI - Messages for maintenance of supporting } \\
\text { information in healthcare systems - Part } 2\end{array}$ \\
\hline CEN ENV 13730-1:2002 & HI - Blood transfusion related messages - Part 1 \\
\hline CEN TS 14822-4:2006 & $\begin{array}{l}\text { HI - General purpose information components - } \\
\text { Part } 4\end{array}$ \\
\hline $\begin{array}{l}\text { ETSI ETR 277 } \\
\text { (March 1996) }\end{array}$ & $\begin{array}{l}\text { SAGE - Requirements specification for an } \\
\text { encryption algorithm for use in audio visual } \\
\text { systems }\end{array}$ \\
\hline $\begin{array}{l}\text { ETSI ETR 278 } \\
\text { (March 1996) }\end{array}$ & $\begin{array}{l}\text { SAGE - Report on the specification and evaluation } \\
\text { of the GSM cipher algorithm A5/2 }\end{array}$ \\
\hline $\begin{array}{l}\text { ETSI SR } 002176 \\
\text { V1.1.1 (2003-03) } \\
\end{array}$ & Algorithms/Parameters for Secure e-Signatures \\
\hline ETSI SR 002298 & ESI - Network and Information Security: \\
\hline V1.1.1 (2003-12) & Proposal for a European Policy Approach \\
\hline ETSI TR 101375 & $\begin{array}{l}\text { SAGE - Report on the specification, evaluation } \\
\text { and usage of GSM GPRS Encryption Algorithm }\end{array}$ \\
\hline$\frac{\text { V1.1.1 (1998-09) }}{\text { ETSI TR } 101690}$ & $\begin{array}{l}\text { and usage of GSM GPRS Encryption Algorithm } \\
\text { SAGE - Rules for the management of GSM CTS }\end{array}$ \\
\hline V1.1.1 (1999-08) & Authentication and Key Generation Algorithms \\
\hline ETSI TR 101740 & SAGE - Rules of the management of the standard \\
\hline V1.1.1 (1999-08) & GSM GPRS Encryption Algorithm 2 (GEA2) \\
\hline ETSI TR 102038 & ESI - TC Security - Electronic Signatures and \\
\hline V1.1.1 (2002-04) & Infrastructures. XML format for signature policies \\
\hline ETSI TR 102047 & International Harmonization of Electronic \\
\hline V1.2.1 (2005-03) & Signature Formats \\
\hline ETSI TR 102272 & Electronic Signatures and Infrastructures (ESI); \\
\hline V1.1.1 (2003-12) & ASN.1 format for signature policies \\
\hline ETSI TS 101733 & Electronic Signature Formats \\
\hline ETSI TS 101862 & Qualified Certificate profile \\
\hline \multicolumn{2}{|l|}{ V1.3.3 (2006-01) } \\
\hline ETSI TS 101903 & XML Advanced Electronic Signatures (XAdES) \\
\hline
\end{tabular}

Table 2. (Continued) 
Table 2. Relevant standards for electronic health record systems

$($ HI $=$ Health Informatics, IT = Information Technologies, SAGE = Security Algorithms Group of Experts, ESI = Electronic Signatures and Infrastructures)

\section{(Continued)}

ETSI TS $102023 \quad$ ESI - Policy requirements for time-stamping

V1.2.1 (2003-01) authorities

\begin{tabular}{|c|c|}
\hline ETSI TS 102176 & ESI - Algorithms and Parameters for Secure \\
\hline V1.2.1 (2005-07) & Electronic Signatures; Parts 1 and 2 \\
\hline ISO 12052:2006 & $\begin{array}{l}\text { HI - Digital imaging and communication in } \\
\text { medicine DICOM (workflow and data } \\
\text { management) }\end{array}$ \\
\hline ISO 17432:2004 & $\begin{array}{l}\text { HI - Messages and communication - Web access } \\
\text { to DICOM persistent objects }\end{array}$ \\
\hline ISO 18232:2006 & $\begin{array}{l}\text { HI - Messages and communication - Format of } \\
\text { length limited globally unique string identifiers }\end{array}$ \\
\hline ISO IEC 13888 & IT - Security techniques - Non-repudiation \\
\hline ISO IEC 14888 & $\begin{array}{l}\text { IT - Security techniques, Digital signature with } \\
\text { appendix, multiple Parts }(1-3) \text {. }\end{array}$ \\
\hline ISO IEC 9796 & $\begin{array}{l}\text { IT - Security techniques, Digital signature scheme } \\
\text { giving message recovery, multiple Parts }(1-2) .\end{array}$ \\
\hline ISO IEC 9797 & $\begin{array}{l}\text { IT - Security techniques, Message authentication } \\
\text { codes. }\end{array}$ \\
\hline ISO IEC 9798 & IT - Security techniques - Entity authentication \\
\hline ISO TR 21089:2004 & HI - Trusted end-to-end information flows \\
\hline NEMA DICOM 3.0 & Digital Imaging and Communications in Medicine \\
\hline CORBA & Common Object Request Broker Architecture \\
\hline $\begin{array}{l}\text { ETSI TS } 101861 \\
\text { V1.3.1 (2006-01) } \\
\end{array}$ & Time stamping profile \\
\hline ISO IEC 27001:2005 & $\begin{array}{l}\text { IT - Security techniques - Information security } \\
\text { management systems (ISMS) - Requirements }\end{array}$ \\
\hline $\begin{array}{l}\text { ISO/IEC 15816:2002 } \\
\text { (ITU-T X.841) }\end{array}$ & $\begin{array}{l}\text { IT - Security techniques - Security information } \\
\text { objects for access control }\end{array}$ \\
\hline $\begin{array}{l}\text { ISO/IEC TR14516:2002 } \\
\text { (ITU-TX.842) }\end{array}$ & $\begin{array}{l}\text { IT - Security techniques - Guidelines for the use } \\
\text { and management of Trusted Third Party services }\end{array}$ \\
\hline $\begin{array}{l}\text { ISO/IEC 15945:2002 } \\
\text { (ITU-T X.843) }\end{array}$ & $\begin{array}{l}\text { IT - Security techniques - Specification of TTP } \\
\text { services to support digital signatures }\end{array}$ \\
\hline ISO IS 17090-1:2002 & HI - Public key infrastructure - Parts 1,2 and 3 \\
\hline ISO TS 21091:2005 & $\begin{array}{l}\text { HI - Directory services for security, communications } \\
\text { and identification of professionals/patients }\end{array}$ \\
\hline ISO TS 21298 & Functional and structural roles \\
\hline ITU-T X.1051 & $\begin{array}{l}\text { Information security management system - } \\
\text { Requirements for telecommunications (ISMS-T) }\end{array}$ \\
\hline
\end{tabular}

Table 2. (Continued) 
Table 2. Relevant standards for electronic health record systems

$($ HI $=$ Health Informatics, IT $=$ Information Technologies, SAGE $=$ Security Algorithms Group of Experts, ESI = Electronic Signatures and Infrastructures)

(Continued)

\begin{tabular}{|c|c|c|}
\hline & $\begin{array}{l}\text { NIST Special } \\
\text { Publication } 800-61\end{array}$ & Computer Security Incident Handling Guide \\
\hline \multirow[t]{13}{*}{ Privacy } & ASTM E1714-00 & $\begin{array}{l}\text { Standard guide for properties of a Universal } \\
\text { Healthcare Identifier }\end{array}$ \\
\hline & ASTM E1987-98 & $\begin{array}{l}\text { Standard guide for individual rights regarding } \\
\text { health information }\end{array}$ \\
\hline & CEN EN 14484:2004 & $\begin{array}{l}\mathrm{HI} \text { - International transfer of personal health data } \\
\text { covered by the EU data protection directive }\end{array}$ \\
\hline & CEN EN 14485:2004 & $\begin{array}{l}\text { HI - Guidance for handling personal health data in } \\
\text { international applications (EU directive) }\end{array}$ \\
\hline & CEN ENV 12924 & $\begin{array}{l}\text { Medical Informatics - Security Categorisation and } \\
\text { Protection for Healthcare Information Systems }\end{array}$ \\
\hline & ISO IEC DTS 25237 & $\begin{array}{l}\text { HI - Pseudonymisation practices for the protection } \\
\text { of personal health information/related services }\end{array}$ \\
\hline & ISO 22857:2004 & $\begin{array}{l}\text { HI - Guidelines on data protection to facilitate } \\
\text { trans-border flows of personal health information }\end{array}$ \\
\hline & ISO TS 21091 & $\begin{array}{l}\text { HI - Directory services for security, communications, } \\
\text { and identification of professionals/patients }\end{array}$ \\
\hline & ISO TS 22600:2006 & $\begin{array}{l}\text { HI - Privilege management and access } \\
\text { control - Parts } 1 \text { and } 2\end{array}$ \\
\hline & OASIS 200201 & $\begin{array}{l}\text { Directory Services Mark-up Language (DSML) } \\
\text { v2.0 }\end{array}$ \\
\hline & OASIS SAML & $\begin{array}{l}\text { Security Assertion Mark-up Language (SAML) } \\
\text { v2.0 }\end{array}$ \\
\hline & OASIS SPML & $\begin{array}{l}\text { Service Provisioning Markup Language (SPML) } \\
\text { v2.0 }\end{array}$ \\
\hline & OASIS XACML & $\begin{array}{l}\text { eXtensible Access Control Mark-up Language TC } \\
\text { v2.0 (XACML) }\end{array}$ \\
\hline \multirow[t]{5}{*}{ Safety } & CEN CR 13694 & $\begin{array}{l}\text { HI - Safety and security related software quality } \\
\text { standards for healthcare (SSQS) CEN Report }\end{array}$ \\
\hline & CEN TR 15299 & $\begin{array}{l}\mathrm{HI} \text { - Safety procedures for identification of patients } \\
\text { and related objects }\end{array}$ \\
\hline & CEN TS 15260 & $\begin{array}{l}\text { HI - Categorisation of risks from health informatics } \\
\text { products }\end{array}$ \\
\hline & ISO DTS 25238 & $\begin{array}{l}\text { HI - Classification of safety risks from health } \\
\text { informatics products }\end{array}$ \\
\hline & ISO TR 21730:2005 & $\begin{array}{l}\text { HI - Use of mobile wireless communication and } \\
\text { computing technology in healthcare facilities }\end{array}$ \\
\hline
\end{tabular}

Table 2. (Continued) 
Table 2. Relevant standards for electronic health record systems

$($ HI = Health Informatics, IT = Information Technologies, SAGE = Security Algorithms Group of Experts, ESI = Electronic Signatures and Infrastructures)

(Continued)

\begin{tabular}{|c|c|c|}
\hline \multirow[t]{7}{*}{ Token } & CEN ENV 13729 & $\begin{array}{l}\text { HI - Secure user identification - Strong } \\
\text { authentication using microprocessor cards }\end{array}$ \\
\hline & CEN ENV 1387 & $\begin{array}{l}\text { Machine readable cards - Health care } \\
\text { applications - Cards: General characteristics }\end{array}$ \\
\hline & CEN ENV 1867 & $\begin{array}{l}\text { Machine readable cards - Health care applications - } \\
\text { Numbering system and registration procedure }\end{array}$ \\
\hline & CEN ENV 13735 & $\begin{array}{l}\text { HI - Interoperability of patient connected medical } \\
\text { devices }\end{array}$ \\
\hline & ISO 20301 & HI - Health cards - general characteristics \\
\hline & ISO 20302 & $\begin{array}{l}\mathrm{HI} \text { - Health cards - numbering system and } \\
\text { registration procedure for issuer identifiers }\end{array}$ \\
\hline & ISO 21549 & HI - Patient health card data \\
\hline \multirow[t]{8}{*}{ Quality } & ASTM E2117-00 & $\begin{array}{l}\text { Guide for identification/establishment of a quality } \\
\text { assurance program for medical transcription }\end{array}$ \\
\hline & CEN CR 13694 & $\begin{array}{l}\text { HI - Safety and security related software quality } \\
\text { standards for healthcare (SSQS). CEN Report }\end{array}$ \\
\hline & ISO 13485:2003 & $\begin{array}{l}\text { Medical devices - Quality management } \\
\text { systems - Requirements for regulatory purposes }\end{array}$ \\
\hline & ISO 14969:2004 & $\begin{array}{l}\text { Medical devices - Quality management systems - } \\
\text { Guidance on the application of ISO } 13485\end{array}$ \\
\hline & ISO 15378:2006 & $\begin{array}{l}\text { Primary packaging materials for medicinal } \\
\text { products. Application of ISO 9001:2000 (GMP) }\end{array}$ \\
\hline & ISO 9000:2005 & $\begin{array}{l}\text { Quality management systems - Fundamentals and } \\
\text { vocabulary }\end{array}$ \\
\hline & ISO 9001:2000 & Quality management systems - Requirements \\
\hline & ISO TS 16949:2002 & $\begin{array}{l}\text { Quality management systems - Particular } \\
\text { requirements for the application of ISO } \\
\text { 9001:2000 }\end{array}$ \\
\hline Policy & ASTM E2212-02a & Standard Practice for Healthcare Certificate Policy \\
\hline \multirow[t]{6}{*}{$\begin{array}{l}\text { Terminology } \\
\text { and Ontology }\end{array}$} & ASTM E1633-02a & $\begin{array}{l}\text { Standard Specification for Coded Values Used in } \\
\text { the Electronic Health Record }\end{array}$ \\
\hline & ASTM E2457-06 & Standard Terminology for Healthcare Informatics \\
\hline & CCOW v1.5 & Clinical Context Object Workgroup Version 1.5 \\
\hline & CEN EN 1068:2006 & HI - Registration of coding systems \\
\hline & CEN EN 12264:2005 & $\begin{array}{l}\text { HI - Categorial structures of systems of concepts - } \\
\text { Model for representation of semantics }\end{array}$ \\
\hline & CEN EN 12435:2006 & $\begin{array}{l}\mathrm{HI} \text { - Expression of the results of measurements in } \\
\text { health sciences }\end{array}$ \\
\hline
\end{tabular}

Table 2. (Continued) 
Table 2. Relevant standards for electronic health record systems

$($ HI $=$ Health Informatics, IT $=$ Information Technologies, SAGE $=$ Security Algorithms Group of Experts, ESI = Electronic Signatures and Infrastructures)

\section{(Continued)}

\begin{tabular}{|c|c|c|}
\hline & CEN EN 13606-2:2010 & $\begin{array}{l}\text { HI - EHR communication Part 2: Archetype } \\
\text { Model }\end{array}$ \\
\hline & CEN EN 15521:2006 & $\begin{array}{l}\text { HI - Categorical structure for terminologies of } \\
\text { human anatomy }\end{array}$ \\
\hline & CEN EN 1614:2005 & $\begin{array}{l}\text { HI - Structure for nomenclature, classification, and } \\
\text { coding of properties in clinical laboratory }\end{array}$ \\
\hline & CEN EN 1828 & $\begin{array}{l}\text { Categorial structure for classifications and coding } \\
\text { systems of surgical procedures }\end{array}$ \\
\hline & CEN EN 1828:2002 & $\begin{array}{l}\text { HI - Categorial structure for classification and cod- } \\
\text { ing systems of surgical procedures }\end{array}$ \\
\hline & CEN ENV 12017 & Medical Informatics Vocabulary (MIVoc) \\
\hline & CEN ENV 12611 & $\begin{array}{l}\text { Categorial structure of systems of concepts - med- } \\
\text { ical devices }\end{array}$ \\
\hline & CEN TS 14463:2006 & $\begin{array}{l}\text { HI - A syntax to represent the content of medical } \\
\text { classification systems (ClaML) }\end{array}$ \\
\hline & HL7v2.XML & HL7 Version 2.5 \\
\hline & ISO 15225:2000 & $\begin{array}{l}\text { Specification for a nomenclature system for med- } \\
\text { ical devices for regulatory data exchange }\end{array}$ \\
\hline & ISO 18104:2003 & $\begin{array}{l}\text { HI - Integration of a reference terminology model } \\
\text { for nursing }\end{array}$ \\
\hline & ISO 19218 & $\begin{array}{l}\text { Medical devices - Coding structure for adverse } \\
\text { event type and cause }\end{array}$ \\
\hline & ISO 20225 & $\begin{array}{l}\text { Global medical device nomenclature for the pur- } \\
\text { pose of regulatory data exchange }\end{array}$ \\
\hline & ISO 21731 & HL7 version 3 - Reference Information Model \\
\hline & ISO TS 17117:2002 & $\begin{array}{l}\text { HI - Controlled health terminology - Structure and } \\
\text { high-level indicators }\end{array}$ \\
\hline & ISO TS 21667:2004 & HI - Health indicators conceptual framework \\
\hline & LOINC & $\begin{array}{l}\text { Logical Observation Identifiers Names and Codes - } \\
\text { Laboratory and clinical observations. }\end{array}$ \\
\hline & SNOMED-CT & $\begin{array}{l}\text { Systematized Nomenclature of Medicine - Clinical } \\
\text { Terms - Clinical Information }\end{array}$ \\
\hline $\begin{array}{l}\text { ID } \\
\text { Management }\end{array}$ & ASTM E1714-00 & $\begin{array}{l}\text { Standard guide for properties of a Universal } \\
\text { Healthcare Identifier }\end{array}$ \\
\hline \& Security & CORBA PIDS & Person Identification Service \\
\hline & HL7/CORBA EIS & Entity Identification Service \\
\hline & HL7 MPI & Master Patient Index \\
\hline & ISO & Digital Object Identifier \\
\hline & LOINC & Logical Observation Identifiers Names and Codes \\
\hline
\end{tabular}


processes for the implementation of interoperable solutions throughout Europe. As ISO/EN 13606 is the European standard for the interoperable exchange of EHR and given the European commitment to deploying interoperable eHealth solutions, this standard is likely to become the European reference frame for the interoperable exchange of EHR and hence there is a need to promote it.

The latest version of the standard defines the syntax and semantics-along with other terminology, security and interface considerations-for the interoperable exchange of EHRs. In spite of the recent approval of the standard (February 2010), it is already being used in some pioneer countries in Europe such as Sweden [14], United Kingdom [15] and Slovak [16]. Furthermore, it is also used in research projects, such as the cooperative Clinical E-Science Framework (CLEF) [17], and in commercial applications, e.g., the Electronic Record Services (ERS) [18]. This review article provides a comprehensive but summarized overview of this standard, since it is the European reference in this context. Additionally, an overview of the EHR standardization arena, enumerating related SDOs and relevant documents, is presented to provide the background context.

\section{THE ISO/EN 13606 STANDARD}

The ISO/EN 13606 standard [9] has been developed by CEN/TC251, the technical committee responsible for developing standards in the field of Health Information and Communications Technology in Europe. ISO/EN 13606 provides a model for representing the information that can be included in an EHR and, at the same time, it defines the information exchange between EHR systems. The main objective of this standard is to define the way that EHRs are exchanged, but it specifies neither the internal architecture of an EHR system nor the way data are stored.

ISO/EN 13606 is based on a dual model: a Reference Model which supports the information, and an Archetype Object Model (AOM). AOM allows defining knowledge, i.e., the concepts of the clinical domain by means of Archetypes. Archetypes are patterns that represent the specific characteristics of the clinical data. A main concept of this dual approach is that if knowledge changes (e.g., additional health characteristics are required to be included), only the archetype under the data will change. For example, the following declaration can be assimilated to knowledge: "A routine blood chemistry measures the following chemical substances in the blood: glucose, urea, creatinine, sodium and potassium". On the other hand, information is the instantiation of that archetype for one patient at one specific point of time: "January $2^{\text {nd }}, 2010$ at 08:43 a.m. John Smith had glucose $=80 \mathrm{mg} / \mathrm{dL}$, urea $=11 \mathrm{mg} / \mathrm{dL}$, creatinine $=$ $0.77 \mathrm{mg} / \mathrm{dL}$, sodium $=141 \mathrm{mmol} / \mathrm{dL}$, and potassium $=4.1 \mathrm{mmol} / \mathrm{dL} "$. Eventually, due to new discoveries in medicine, it may become important to include additional measurements (for example, chlorine levels) in the routine blood chemistry tests. In such a case, only the archetype (knowledge) would change while the Reference Model remains unaltered. The ISO/EN 13606 standard is divided into five different parts that are detailed below:

- Part 1: Reference Model. This part defines basic generic components that support information and the relationships between those components. Figure 2 (extracted from ISO/EN13606-1) shows a simplified scheme of these components. 


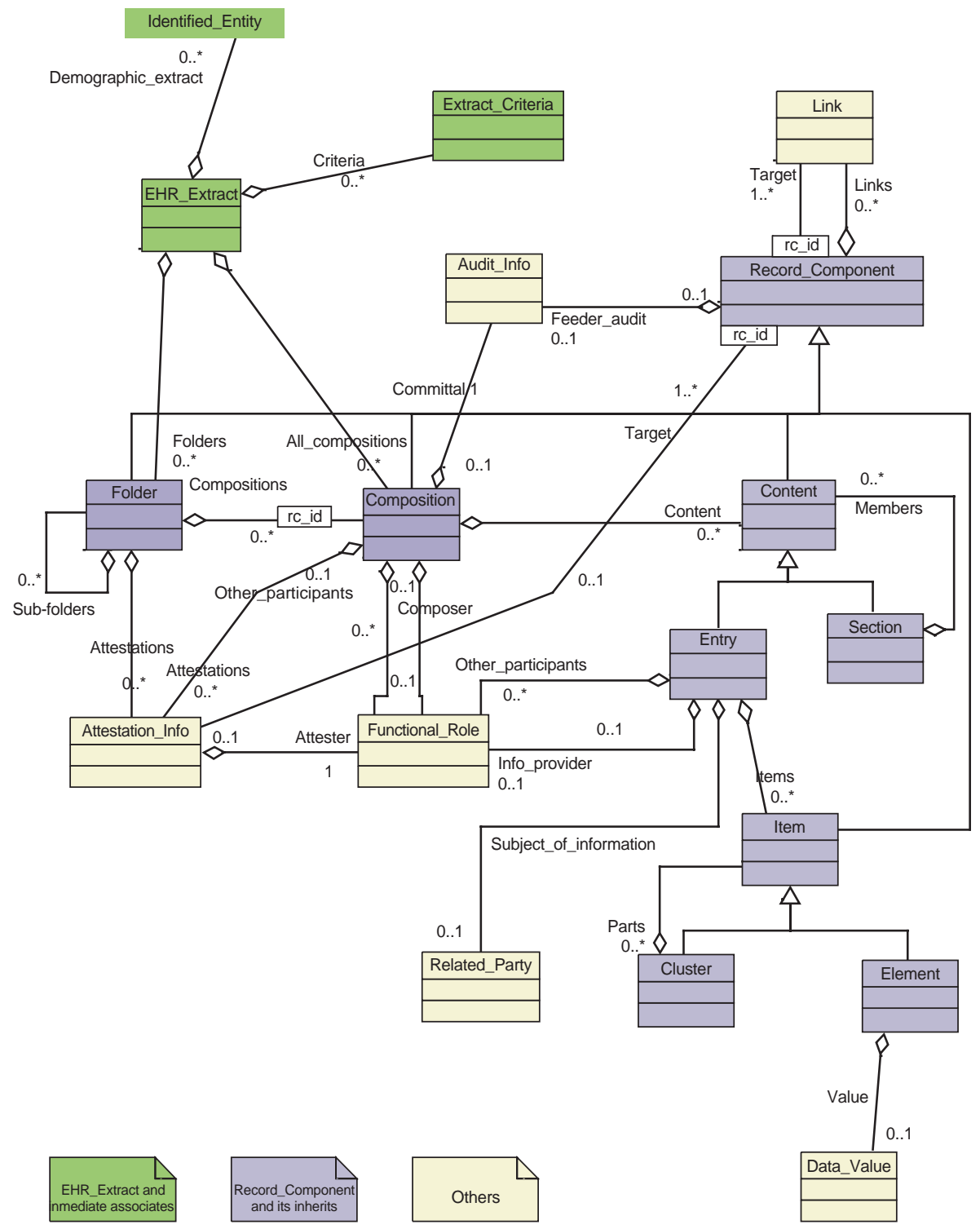

Figure 2. ISO/EN13606 Reference Model (simplified scheme from ISO/EN13606-1).

The EHR is comprised of the following logic blocks (Figure 3):

- EHR_Extract: The top-level container of part or all of the EHR of a patient.

- Folder: Some high level organization within an EHR (episode of care, compartments of care, etc.) 


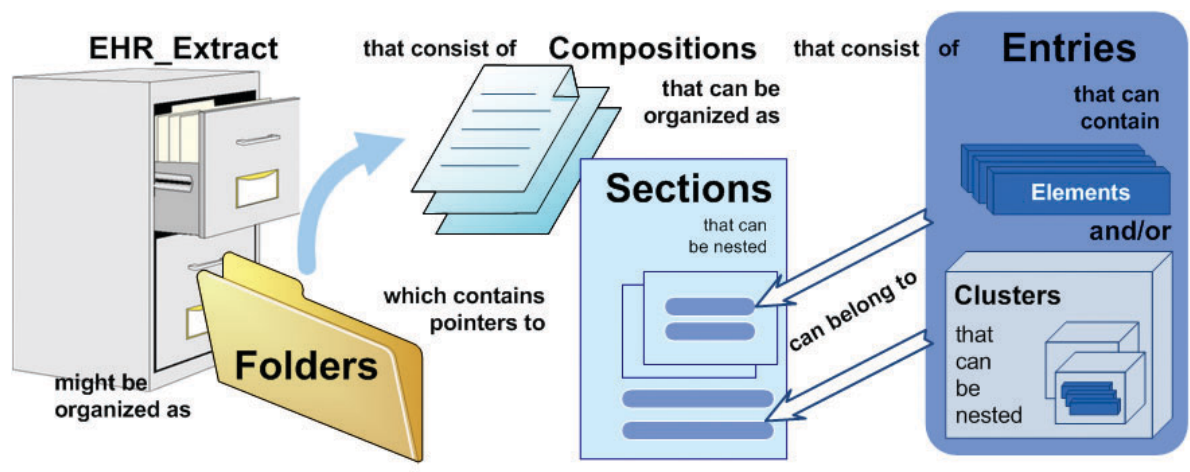

Figure 3. Component relationships of the ISO/EN13606 Reference Model.

- Composition: A single clinical encounter or record documentation session (reports, test results, etc.)

- Section: Clinical headings reflecting flow information (subjective symptoms, findings, treatment, etc.).

- Entry: Clinical statements (a measurement, a symptom, etc.).

- Clusters: The means to organize nested multi-part data structures (tables, time series, etc.)

- Element: A container of a single data value. This is the leaf node of the hierarchy.

Thus, the Reference Model sets hierarchical relationships between its components, achieving in this way syntactic interoperability, i.e., identifying different elements in the system and establishing rules for combining them, thus allowing any system to be able to understand the structure of the information. A deeper analysis shows other relevant characteristics related to the use of the standard, such as the following:

- The ability of signing every single element by means of defining the ATTESTATION_INFO class. As can be seen, the existing association relationship between this class and RECORD_COMPONENT is inherited by the rest of the elements, given that all of them derive from this abstract class. Thus, every RECORD_COMPONENT can be signed independently.

- The separation of the demographic information allows transmitting clinical information anonymously, an essential factor in health environments for security reasons. All components of the system (organizations, devices, healthcare professionals, subjects of care or other classes of people) are identified by unique identifiers.

- Auditory capabilities are present through the AUDIT_INFO class, which can be used to track what data has been introduced, when and by whom, and also the reason for that information to be modified.

- To achieve this, the Reference Model establishes a mechanism of versioning records; thus deletion is not allowed (if a record needs to be removed, it is marked as non-valid).

- It also allows recording every single request to the EHR system, whether accepted or not, as well as the reason for the rejection. 
- $\quad$ Part 2: Archetype Model. The Archetype Model represents the semantics of the dual model approach. An archetype is used for modelling domain concepts (blood pressure, body weight, etc.), constraining the Reference Model at runtime by defining the structure of the instance and/or limiting the value range of an attribute (see Figure 4). Since this part of the norm leverages appropriate parts of the openEHR model for defining archetypes, openEHR and ISO/EN13606 share the basis of the archetype model [19].

Archetypes can make use of standardized health terminology to simplify the decoding of the received data and they are defined using different formal languages such as the Ontology Web Language (OWL) and the Archetype Definition Language (ADL) [20]. In Figure 5, the top-level structure of an ADL archetype is represented. The current version of ADL language (v1.4) uses three syntaxes to describe constraints on data:

- cADL: constraint form of ADL, used to express the archetype definition section.

- dADL: data definition form of ADL, used to express data that appears in the language, description, ontology, and revision_history sections.

- First-Order Predicate Logic (FOPL), to express data which appears in the declarations and invariant sections.

Figure 6 shows a simplified scheme of the Archetype Model, extracted from ISO/EN13606-2. Describing a well defined archetype is not a simple task. As seen in Figure 6, the ISO/EN 13606 standard offers different mechanisms to enable this modelling, such as the archetype_description, the ontology and the constraint_model.

\section{Information}

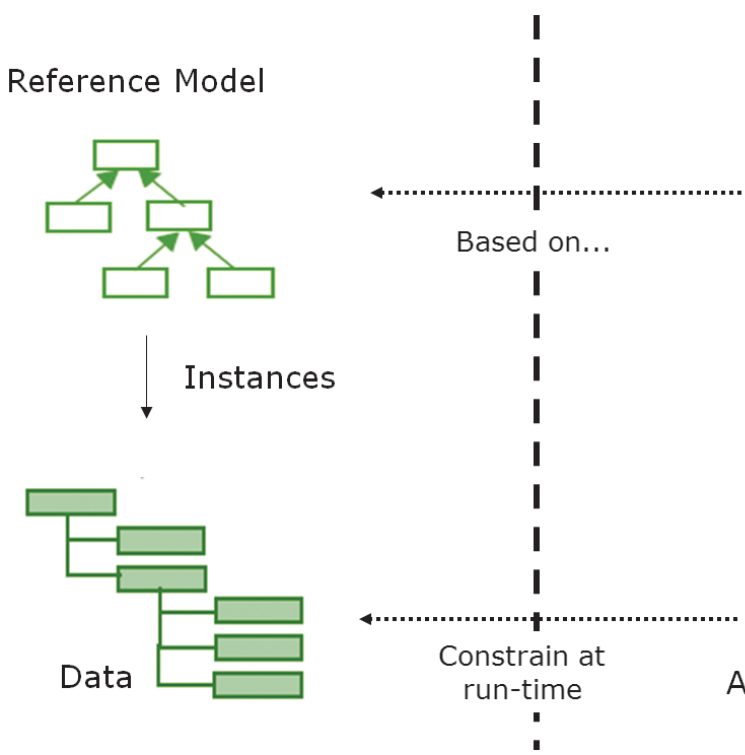

\section{Knowledge}

Archetype Model
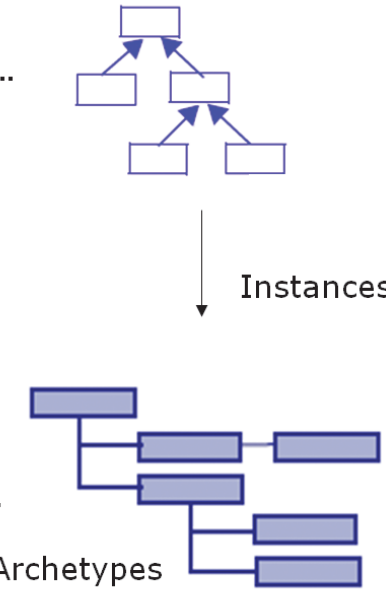

Instances

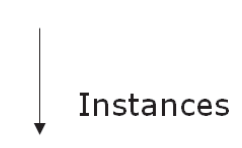

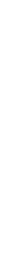

Figure 4. Relationship between information (instances of Reference Model) and knowledge (instances of Archetype Model) [19]. 


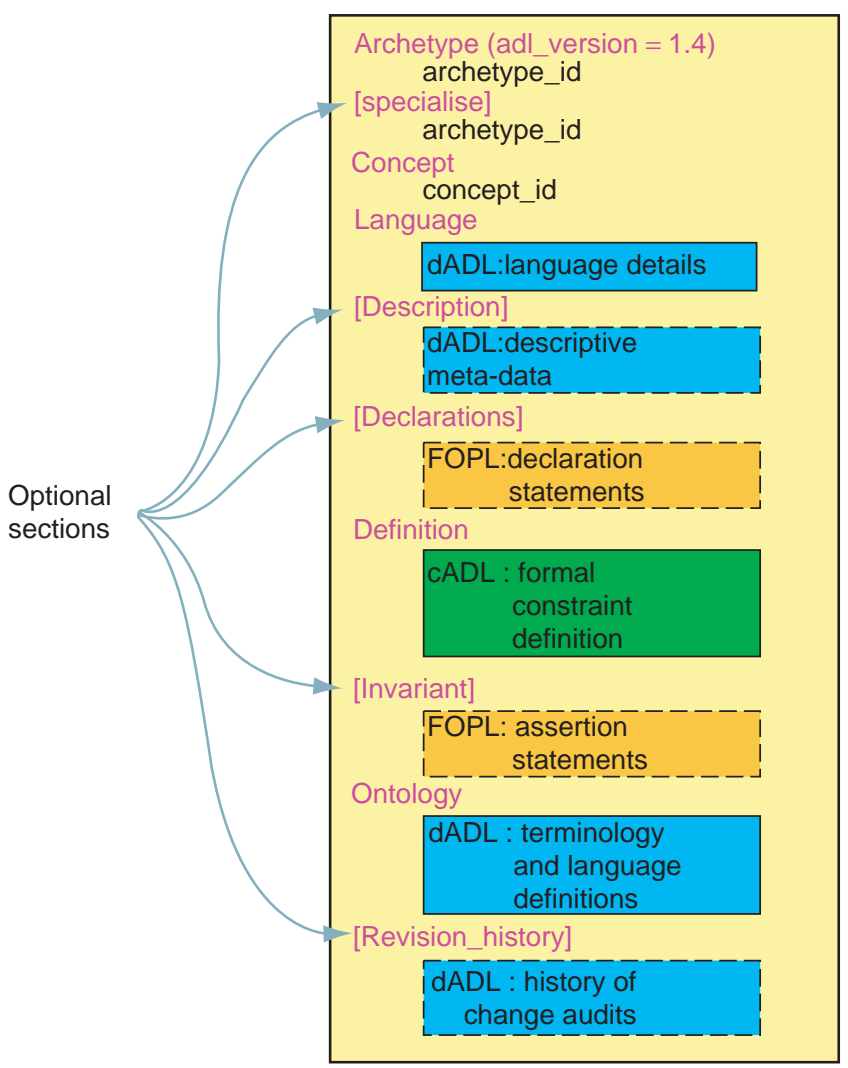

Figure 5. Top-level structure for an Archetype Definition Language (extracted from ISO/EN13606-2).

The archetype_description allows associating additional data (metadata) to the archetype, for instance, a translation into a different language. The ontology is used to bind archetype nodes to specific health terms. Finally, the constraint_model specifies a hierarchical schema that defines how an instance must be built.

Although the main feature of ISO/EN 13606 is the dual model, described in the first two parts, it is also important to define other aspects in order to achieve interoperable exchange of EHR, such as nomenclature issues (part 3), security issues (part 4) and interfacing for querying (part 5).

- Part 3: Reference Archetypes and Term lists. This part establishes a normative set of coded terms, each one defining a controlled vocabulary for a Reference Model attribute contained in ISO/EN 13606-1. This part includes different groups of terms such as terms related to the subject of an Entry (SUBJECT_CATEGORY), the category of information of any ELEMENT or 


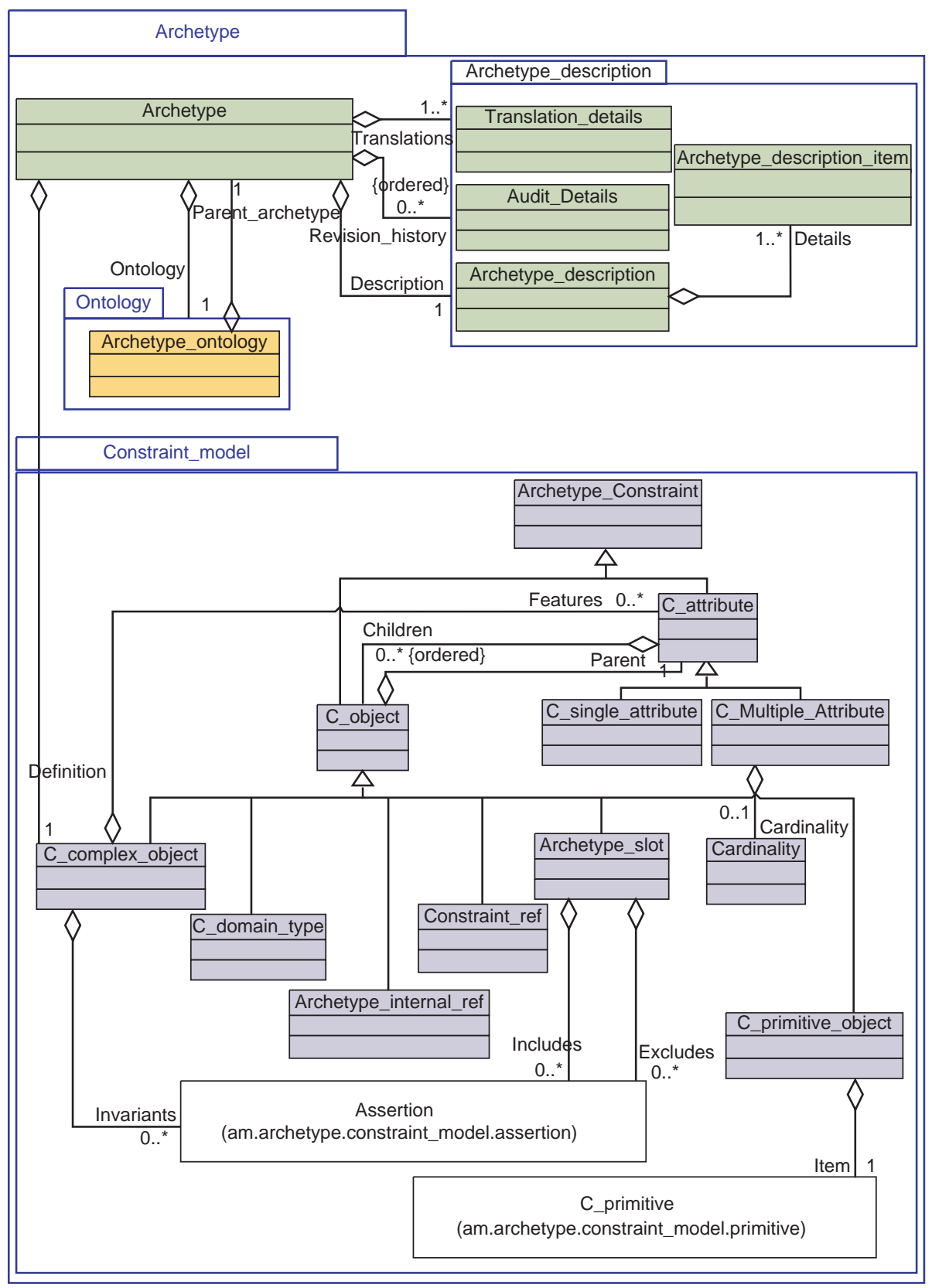

Figure 6. Archetype model (simplified scheme from ISO/EN13606-2). 
CLUSTER (ITEM_CATEGORY), the status of a particular version of a record_component (VERSION_STATUS), the physical or electronic means by which an Entity participates $(M O D E)$, the act status values for a particular Entry as included in EN 12967-3 [21] - the computational viewpoint of Health Informatics Service Architecture (HISA) - (ACT_STATUS), the semantics of the relationship between the source and target record_component (LINK_NATURE) and a subcategory of the corresponding link terms (LINK_ROLE), and finally, the structural organization of a Cluster (STRUCTURE_TYPE).

- $\quad$ Part 4: Security. This part describes a methodology for specifying the privileges necessary to access EHR data and some other general security requirements that should apply to EHR communications. For example, it provides a double input table, the functional role of the requester and the sensitivity of the record. The information is only accessible if the functional role of the requester (coded with a number) is at least equal to the sensitivity of the record. This security part also defines both general and specific access policies able to deny or grant access to identified parties or specific functional roles.

- Part 5: Interface Specification. This part describes a set of interfaces to request access to the information and resolve the request. Three specific interfaces are defined:

- REQUEST_EHR_EXTRACT, to request a specific EHR_EXTRACT (as defined in ISO/EN 13606-1). The only mandatory parameter is subject_of_care_identity, but optional parameters are also available. These optional parameters can be used to specify the time range of the retrieved information (for example, it is possible to request either all previously requested records or any record within a given time range).

- REQUEST_ARCHETYPES, to request one or more ARCHETYPES (as defined in ISO/EN 13606-2). There is no mandatory parameter in this case. Archetypes can be requested based on a particular concept (for example, it is possible to request a specified set of identified archetypes or all the archetypes).

- REQUEST_EHR_AUDIT_LOG_EXTRACT, to request a specific EHR_ AUDIT_LOG_EXTTRACT (as defined in ISO/EN 13606-4). In a manner analogous to REQUEST_EHR_EXTRACT, it defines optional parameters to filter the retrieval of information and to determine access policies, since special privileges are required to access specific control information.

The ISO/EN13606 standard has been recently completed after Part 5 was ratified by ISO and CEN in February 2010. As a multipart standard, the different parts were approved by separate polling, while further comments in the voting process led to changes in some parts. The ratification dates for the 5 parts of the standard by CEN and ISO are shown in Table 3.

The mandatory attributes required to be transmitted as well as the data types and their meaning within the standard are shown in Table 4. Additionally, other relevant information can be expressed by including optional parameters. For instance, information such as the date and the time interval the item was observed, a screenshot of the test or even information related to whether the extract has been automatically generated by a machine or triggered by any other provider. Moreover, by the use of the optional attributes archetype_id and meaning semantic interoperability can be provided by specifying the archetype that has been used or if that record conforms to any concept domain that uses health terminology like SNOMED-CT [22]. The observed item should 
Table 3. Ratification dates for the 5 parts of ISO/EN13606 by CEN and ISO

\begin{tabular}{llc}
\hline & \multicolumn{1}{c}{ Status in CEN } & Status in ISO \\
\hline $\begin{array}{l}\text { ISO/EN13606- } \\
\text { Part 1: Reference Model }\end{array}$ & Published in February 2007 & Published in February 2008 \\
\hline $\begin{array}{l}\text { ISO/EN13606- } \\
\text { Part 2: Archetype Model }\end{array}$ & Published in July 2007 & Published in November 2008 \\
$\begin{array}{l}\text { ISO/EN13606-Part 3: } \\
\text { Reference Archetypes }\end{array}$ & Published in February 2008 & Published in January 2009 \\
$\begin{array}{l}\text { and Term Lists } \\
\text { ISO/EN13606- }\end{array}$ & Published in March 2007 & Published in September 2009 \\
$\begin{array}{l}\text { Part 4: Security } \\
\text { ISO/EN13606-Part 5: }\end{array}$ & Published jointly by CEN and ISO in February 2010 (according \\
Interface Specification & to the Vienna Agreement) & \\
\hline
\end{tabular}

be expressed in the optional attribute value in ELEMENT, failing which it must be indicated by the null_flavour attribute inherited from RECORD_COMPONENT.

To date, the ISO/EN 13606 standard has been based on a subset of CEN/TS14796 for describing data types but this is expected to change in the future. Due to the Memorandum of Understanding [23] between HL7, CEN/TC251 and the Joint Initiative on SDO [24], a new document is being discussed in order to harmonize CEN data types (CEN/TS14796) and HL data types. This document (ISO/FDIS 21090), still in draft status, is being designed to replace CEN/TS14796 and align with HL7 data types. The number of classes defined in ISO/FDIS 21090 is higher than in CEN/TS14796, particularly in the case of structured text, since it is intended to cover all those records that were previously stored as free text. Another point to take into account is the intention of including specific classes to represent information related to the demographic package, such as addresses or entity names.

Another remarkable feature of ISO/EN 13606 is the alignment it presents to other relevant standards shown in Table 1:

- $\quad$ Part 1 can be seen as a subset of the openEHR Reference Model and presents a partial alignment with HL7 Clinical Document Architecture (CDA) Release 2.0. It can also be mapped to relevant portions of EN12796, EN13940, and specific metadata of the IHE Cross Enterprise Document Sharing (XDS).

- $\quad$ Part 2 leveraged the openEHR model and its requirements have been adopted with minor revision by HL7.

- $\quad$ Part 3 contains mapping to HL7 Act Relationship codes, ACT_STATUS TERMS mapped with HISA, etc.

- $\quad$ Part 4 aligns with ISO 22600 and has been contributed to IHE in defining its privacy management services.

- $\quad$ Part 5 can be considered as a specialization of HISA services relating to clinical data and to clinical knowledge, and most parts of it can be mapped to IHE XDS query parameters. 


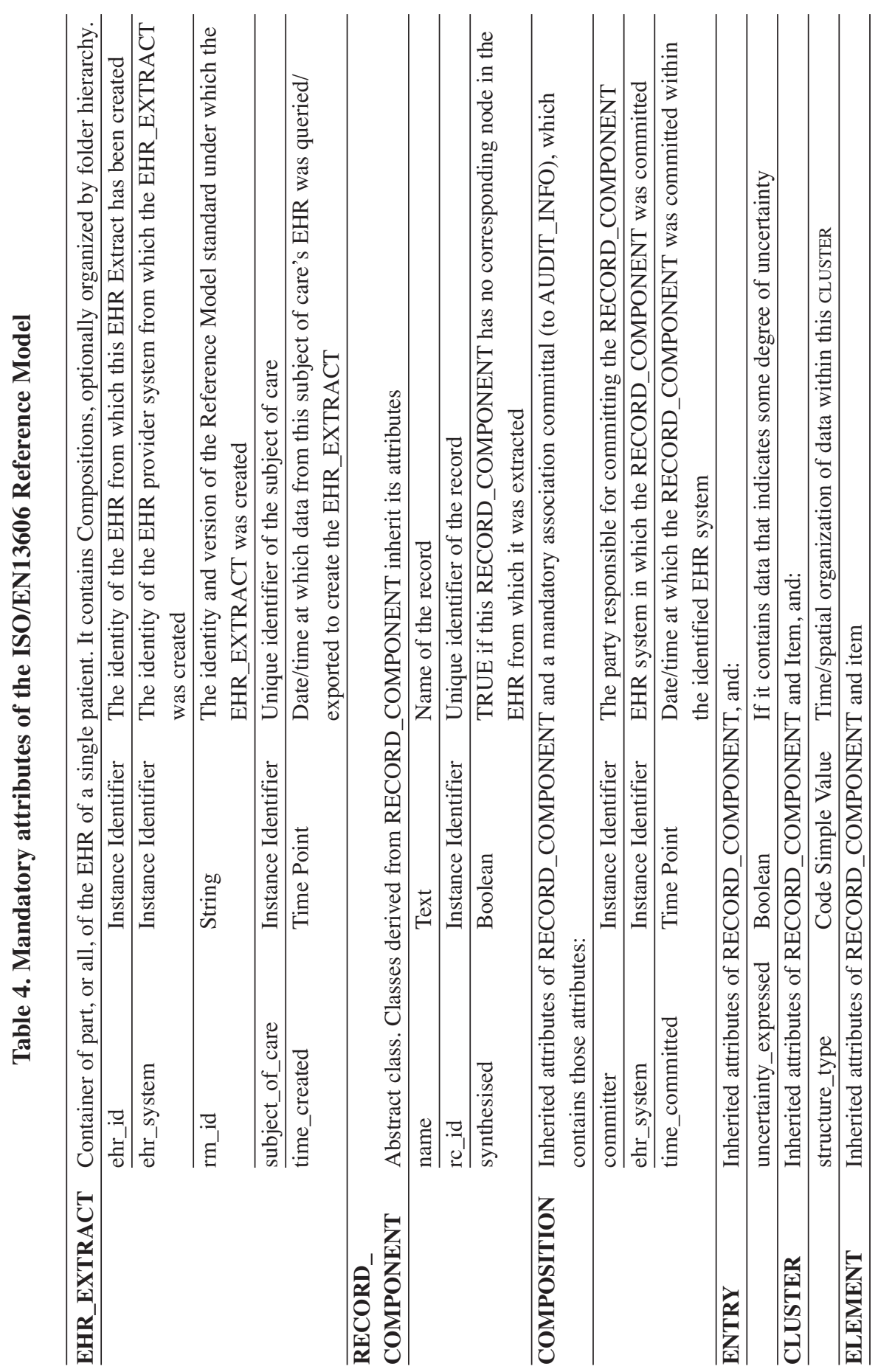




\section{FORTHCOMING CHALLENGES FOR THE EHR}

ISO/EN 13606 is a very recent standard (it was fully completed on February 2010). Hence, there is still a wide range of further research to be carried out, as was concluded in the "CEN/ISO EN13606 Invitational Workshop" [25]. Around 40 people from twelve countries were selected as representatives of the different projects that have adopted the ISO/EN 13606 standard. Those attending the workshop shared best implementation practices and identified the main problems and future challenges related to the ISO/EN 13606 standard. Since the standard is in its early stages and it does not state the implementation technologies to be used, one of the drawbacks discussed was the lack of resources or implementation guides. Regarding this issue, attendants agreed to collaborate in many ways, for example, by creating educational resources and good practices for the adoption of the standard or by developing technical artefacts, such as eXtensible Markup Language (XML) schemas and implementation guidelines, that will enable the standard to be adopted more easily and used consistently. Another drawback discussed was the absence of archetype governance. The potential of developing proprietary archetypes may prevent the sharing of knowledge. Regarding this issue, two main axes of action were suggested: the creation of regional or national archetypes repositories and the development and sharing of tools for creating archetypes for use with SNOMED-CT and other terminologies. Both axes would contribute to enhancing quality in modelling clinical concepts. In this context, the importance of developing Detailed Clinical Models (DCM) - i.e., new ways to structure health information by combining expert knowledge, data specification and terminologies-and certifying specifications to generate them was also covered. Another issue addressed was the global problem of the identification of patients or healthcare professionals in order to release functional ISO/EN 13606 EHR systems. After the main drawbacks were identified, attendants agreed to develop an ISO/EN 13606 community of users and study other future mechanisms of collaboration with the objective of publicizing best practices based on real implementations and providing feedback for work in CEN, ISO and in conjunction with existing organizations such as openEHR, the International Health Terminology Standards Development Organization (IHTSDO), and EuroRec [26].

Additionally, the exchange of clinical information with the emerging Personal Health Records (PHR) systems is a closely related challenge. A PHR system is essentially an EHR system but the main distinction, as pointed out by ISO, is that in PHRs the individual who is the subject of the record is the key stake-holder determining its content and with rights over that content. Several commercial PHR systems, such as Microsoft Health Vault [27], Google Health [28] or Dossia [29] are already available and all of them allow tracking the health status and the evolution of any measurement record of the patient. All these systems contain information eligible to be included in EHR Systems in order to improve the continuity of care of the patient. A new ISO item of work (ISO/NWIP \#14292 Health Informatics) has been launched to define PHR, its scope, context and global variations of use.

There are other parallel challenges, such as systems quality, in improving EHRs. EHRs are not always as functional as may be desired, and at times they do not meet 
minimum interoperability requirements. A parallel European project is being conducted to establish systematic and comparable certification procedures for assuring the quality of eHealth products. One of the most important functions of EHR is to provide continuity of care, but EHRs are also legal documents, potentially used for research, teaching, etc.

\section{CONCLUSION}

The exchange of clinical information is a crucial factor to enable provision of high quality health services. The application of ICT in this process vastly improves the management and exploitation of traditional health records. However, the development of non-standardized, heterogeneous communication architectures has caused syntactic and semantic divergences. The internationally adopted strategy to overcome the interoperability gap is the application of standards that provide descriptions of all the elements involved, such as syntactic, structural and semantic interoperability. The ISO/EN 13606 standard covers the entire EHR needs within its five parts and, since its final approval in February 2010, it has gained steadily growing acceptance by being implemented, supported or adopted by several European projects, academic institutions, hospitals and health organizations. The main technical improvement of ISO/EN 13606 is its dual model approach, which provides a clear separation between information (Reference Model) and knowledge (Archetype Model). The interaction of these two models vastly improves the capability for developing and sustaining up-to-date, medically-accurate information systems. Besides the reference and information models, the standard provides three additional normative parts. These parts address essential issues in the conception of modern EHR systems such as normative, controlled nomenclature (part 3), security methodology and specifications (part 4), and interface definitions to request specific extracts, archetypes or audit log extracts (part 5). Thus, the recently published ISO/EN 13606 standard bridges the existing interoperability gap by providing a normative framework for building interconnected, standardized EHR systems.

\section{ACKNOWLEDGEMENT}

The authors wish to thank Dipak Kalra (head of the CEN/TC 251-WG1 Task Force 13606: Electronic Health Record Communication, EHRCom) for his help and support. This research work has been partially supported by projects TIN-2008-00933/TSI from Ministerio de Ciencia e Innovación (MICINN) and European Regional Development Fund (ERDF), TSI-020100-2010-277 and TSI-020302-2009-7/Plan Avanza I+D from Ministerio de Industria, Turismo y Comercio (MITyC), and PI029/09 from Gobierno de Aragón.

\section{REFERENCES}

[1] Health Information Management Systems Society (HIMSS). Electronic Health Record definition. Accessed October 2010. Available: http://www.himss.org/ASP/topics_ehr.asp.

[2] L. Rosmus, "Electronic Health Records: Benefits \& Drawbacks", University of Alberta Health Sciences Journal, vol. 2, issue 1, pp. 38-41, 2005. 
[3] NIH National Centre for Research Resources, "Electronic Health Records Overview," 2006. Accessed October 2010. Available: http://www.ncrr.nih.gov/publications/informatics/ehr.pdf.

[4] Vienna Agreement on technical co-operation between ISO and CEN. ISO Council resolution 35/2001, 2001. CEN Administrative Board resolution 2/2001, 2001. Accessed October 2010. Available: http://isotc.iso.org/livelink/livelink/fetch/2000/2122/3146825/4229629/4230450/4230458/01_. Agreement_on_Technical_Cooperation_between_ISO_and_CEN_Vienna_Agreement_pdf?nodei $d=4230688 \&$ vernum $=0$.

[5] B. Blobel, “Advanced EHR architectures: promises or reality”, Methods Inf Med, vol. 25, pp. 95-101, 2006.

[6] European Quality labelling and Certification of Electronic Health Record systems (Q-EHR), "Inventory of Relevant Standards for EHR Systems", January 2007. Accessed October 2010. Available: http://www.eurorec.org/services/standards/Q-REC-Eurorec_Overview\%20on\%20EHR\%20 Standards\%2001.pdf.

[7] HL7. Health Level Seven. Accessed October 2010. Available: http://www.hl7.org/.

[8] openEHR. Accessed October 2010. Available: http://www.openehr.org/home.html.

[9] ISO/EN13606. CEN/TC251-ISO/TC215. Electronic Healthcare Record (EHR) Communication. Parts 1: Reference Model, Part 2: Archetype Model, Part 3: Reference Archetypes and Term lists, Part 4: Security and Part 5: Interface Specification. Accessed October 2010. Available: http://www.iso.org/ iso/catalogue_detail.htm? csnumber $=40784$.

[10] Commission of the European Communities. Proposal for a directive of the European Parliament and of the Council on the application of patients' rights in cross-border healthcare. 2008/0142 (COD). Accessed October 2010. Available: http://ec.europa.eu/health/ph_overview/co_operation/ healthcare/docs/COM_en.pdf.

[11] Commission of the European Communities. Commission recommendation on cross-border interoperability of electronic health record systems. (2008/594/EC). Accessed October 2010. Available: http://eurlex.europa.eu/LexUriServ/LexUriServ.do? uri=OJ:L:2008:190:0037:0043:EN:PDF.

[12] epSOS Project. Accessed October 2010. Available: http://www.epsos.eu/.

[13] ARGOS e-Health. Accessed October 2010. Available: http://argos.eurorec.org/.

[14] The Swedish National Patient Overview Project. Accessed October 2010. Available: http://www. cehis.se/vardtjanster/npo/.

[15] Logical Record Architecture (LRA). Accessed October 2010. Available: http://www. connectingforhealth.nhs.uk/systemsandservices/data/lra.

[16] National Health Information Centre (NHIC). Accessed October 2010. Available: http://www.nczisk.sk/ buxus/generate_page.php?page_id=560.

[17] J. Rogers et al, "A Co-operative Clinical E-Science Framework (CLEF): Joining up Healthcare and Clinical Research". Accessed October 2010. Available: http://www.health-informatics.org/ hc2004/P31_Taweel.pdf.

[18] Electronic Record Services (ERS). Accessed October 2010. Available: http://www.e-recordservices.eu/.

[19] T. Beale, "openEHR architecture-Architecture overview", openEHR Foundation. Accessed October 2010. Available: http://www.openehr.org/releases/1.0.1/architecture/overview.pdf.

[20] T. Beale, “Archetype Definition Language ADL 1.4”, openEHR Foundation. Accessed October 2010. Available: http://www.openehr.org/releases/1.0.1/architecture/am/adl.pdf.

[21] ISO/EN12967 (HISA). CEN/TC251-ISO/TC215. Health Informatics. Service Architecture. Part 1: Enterprise viewpoint, Part 2: Information viewpoint, Part 3: Computational viewpoint. Accessed October 2010. Available: http://www.iso.org/iso/catalogue_detail.htm? csnumber=50500.

[22] SNOMED-CT. International Health Terminology Standards Development Organization (IHTSDO). Accessed October 2010. Available: http://www.ihtsdo.org/.

[23] Memorandum of Understanding on Intensifying the collaboration between CEN/TC 251 and HL7. Accessed October 2010. Available: http://www.hl7.org/documentcenter/public/mou/CEN-TC251.pdf. 
[24] Joint Initiative on Standards Development Organizations. Accessed October 2010. Available: http://www.global-e-health-standards.org/.

[25] CEN/ISO EN13606 invitational workshop. Accessed October 2010. Available: http://pangea.upv.es/ en13606/index.php/en13606-invitational-workshop-madrid-june-2010.

[26] European Institute for health Records (EuroRec) Accessed October 2010. Available: http://www. eurorec.org/.

[27] Microsoft Health Vault. Accessed October 2010. Available: http://www.healthvault.com/.

[28] Google Health. Accessed October 2010. Available: http://www.google.com/intl/en-US/health/tour/.

[29] Dossia Personal Health Platform. Accessed October 2010. Available: http://www.dossia.org/. 


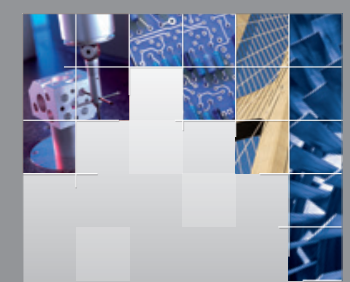

\section{Enfincering}
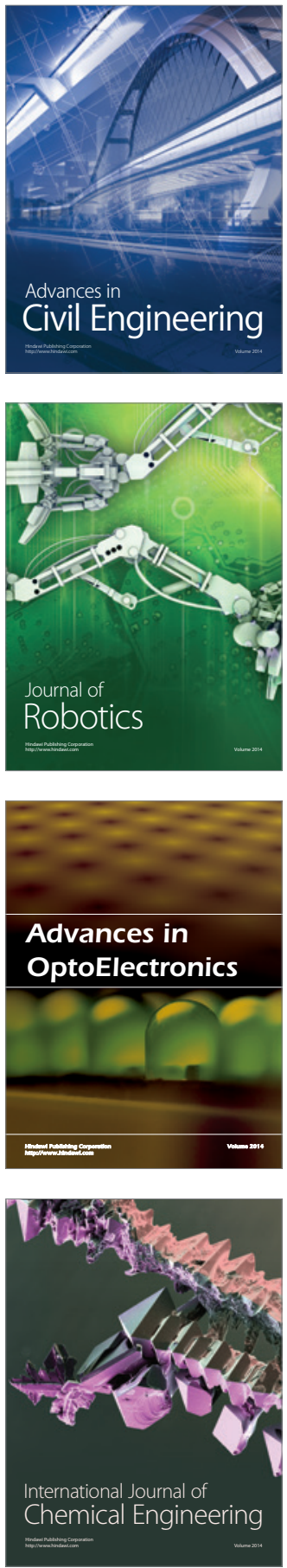

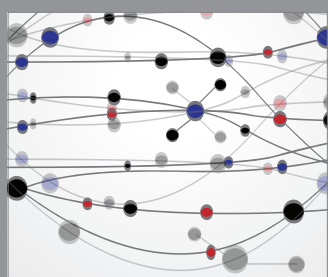

The Scientific World Journal

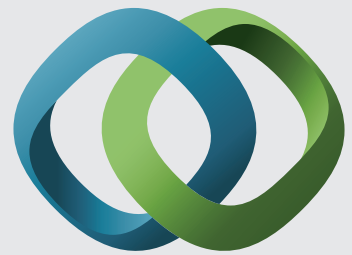

\section{Hindawi}

Submit your manuscripts at

http://www.hindawi.com
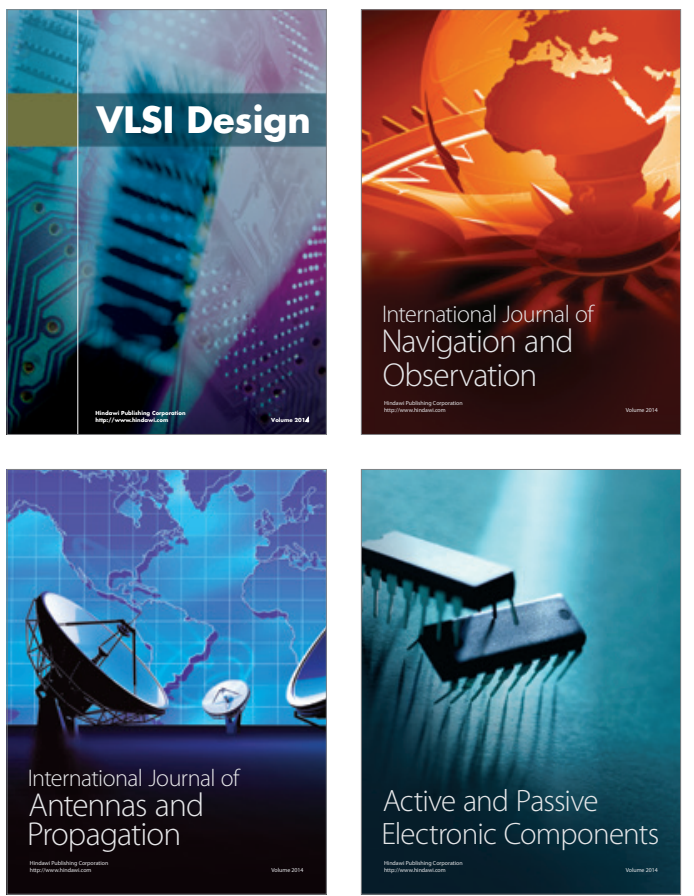
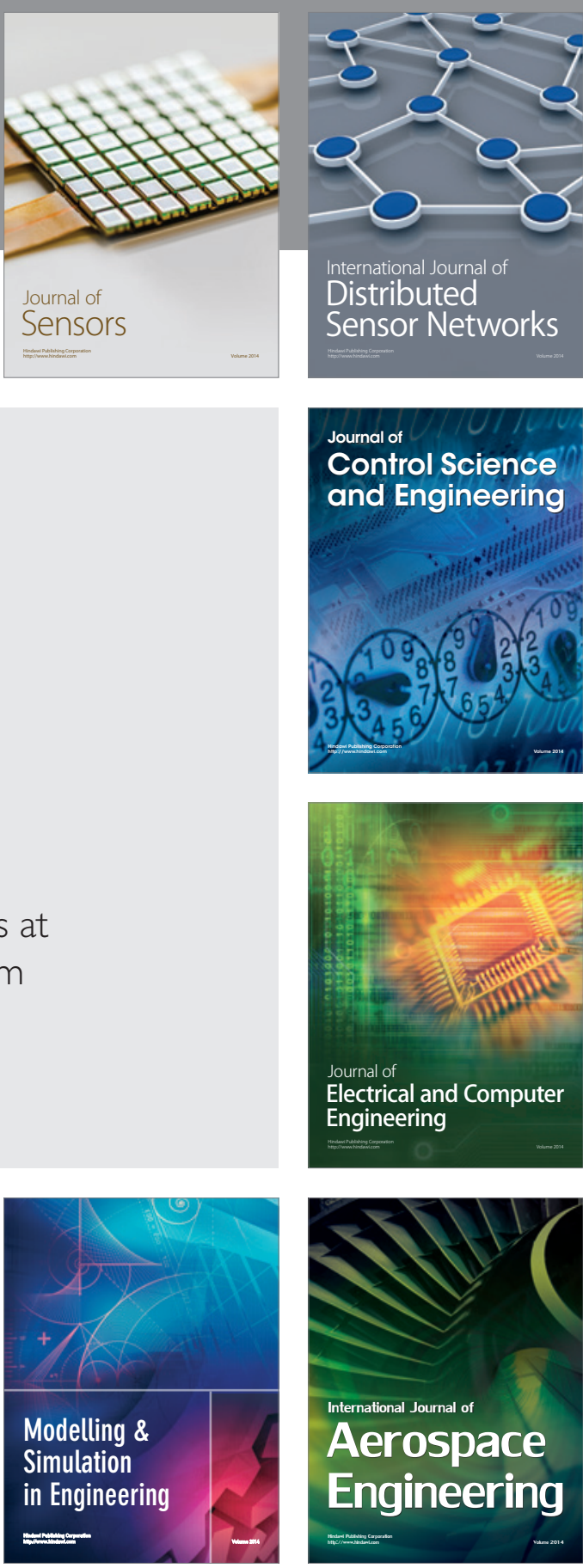

International Journal of

Distributed

Sensor Networks

Journal of

Control Science

and Engineering
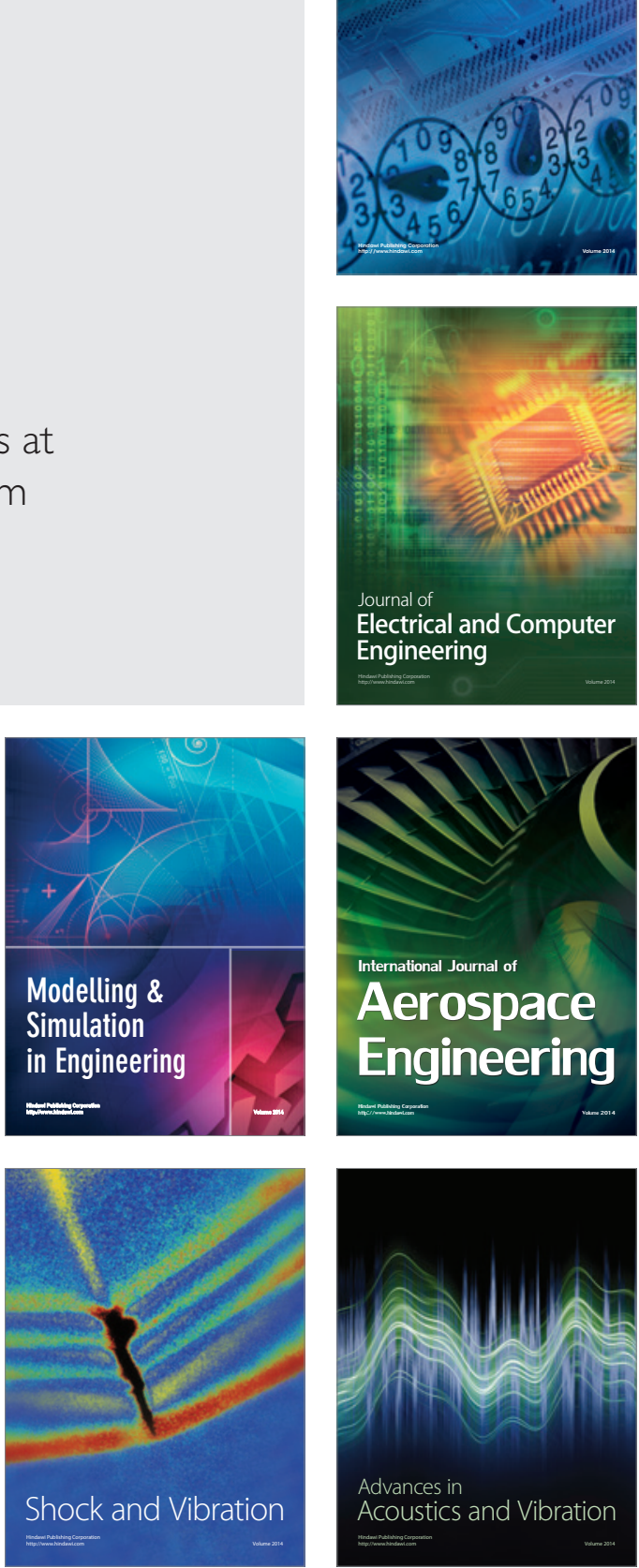